\title{
Mengais Asa untuk Kampung 1001 Malam
}

\author{
Suprihatin, Aprianto WS, Firman P, Yuniar KS, Alfenia A, Revianti KD \\ Program Studi Ilmu Komunikasi \\ Sekolah Tinggi Ilmu Komunikasi-Almamater Wartawan Surabaya \\ Nginden Intan Timur I/18 Surabaya \\ Email:meetitien@gmail.com
}

\begin{abstract}
Kampung 1001 Malam is a dense settlement under Dupak Surabaya toll bridge. The named is consider the condition of the settlement which is always dark due to the lack of light in the village. Apart from always being in the night (dark), the village is slum and untouched by development. This village is inhabited by residents who mostly work as scavengers, construction workers, or beggars. Marginalized groups who are marginalized from economic, social and political access. An irony considering its existence right under the symbol of city development, the toll road. This article is the result of research that started the Stikosa-AWS student community service program in the form of a documentary video about Kampung 1001 Malam. In addition to the video, students also provided educational assistance packages to residents. Although limited, these two activity options had to be taken because the free education program for school dropouts in the village could not be implemented due to the pandemic.
\end{abstract}

Keywords: Kampung 1001 Malam, toll bridge, community development, marginal.

\begin{abstract}
Abstrak
Kampung 1001 Malam adalah sebuah pemukiman padat di bawah jembatan tol Dupak Surabaya. Dinamai demikian mengingat kondisi pemukiman yang selalu gelap karena kurangnya cahaya di kampung itu. Selain selalu berada dalam suasana malam (gelap), kampung tersebut kumuh dan tak tersentuh pembangunan. Kampung ini dihuni oleh warga yang rata-rata bekerja sebagai pemulung, buruh bangunan, atau pengemis. Kelompok marjinal yang terpinggirkan dari akses ekonomi, sosial, dan politik. Suatu ironi mengingat keberadaannya yang tepat di bawah simbol pembangunan kota, jalan tol. Artikel ini merupakan hasil penelitian yang mengawali program pengabdian masyarakat mahasiswa Stikosa-AWS berupa pembuatan video dokumenter tentang Kampung 1001 Malam. Selain video tersebut mahasiswa juga memberikan paket bantuan pendidikan kepada warga. Meski terbatas, dua pilihan kegiatan tersebut terpaksa diambil karena program pendidikan gratis bagi anak-anak putus sekolah di kampung itu tidak dapat dilaksanakan akibat pandemi.
\end{abstract}

kata kunci: kampung 1001 malam, jembatan tol, pengabdian masyarakat, marjinal.

\section{PENDAHULUAN}

Kebijakan pemerintah untuk terus mendorong percepatan pembangunan infrastruktur di berbagai daerah merupakan satu upaya untuk melakukan pemerataan pembangunan. Sayangnya, bersama tujuan tersebut, percepatan pembangunan infrastruktur di sisi lain mengakibatkan berbagai dampak sosial. Salah satunya adalah berkurang, terhambat, dan bahkan terlanggarnya pemenuhan HAM bagi sebagian kelompok masyarakat. Melalui Peraturan Presiden (Perpres) Nomor 3 Tahun 2016 tentang Percepatan Pelaksanaan Proyek Strategis Nasional yang diterbitkan pada tanggal 8 Januari 2016, berbagai proyek berskala besar dilaksanakan. Meski dalam Perpres ini dinyatakan bahwa Proyek Strategis Nasional 
adalah proyek yang dilaksanakan oleh pemerintah, pemerintah daerah, dan atau badan usaha yang memiliki sifat strategis untuk meningkatkan pertumbuhan dan pemerataan pembangunan dalam upaya meningkatkan kesejahteraan masyarakat dan pembangunan daerah, namun dalam realitanya warga justru menjadi korban terdampak dari berbagai mega proyek yang dilakukan.

Alih-alih menerima manfaat dari pembangunan, sebagian warga terdampak ini justru makin terpuruk dan harus hidup lebih miskin dari sebelumnya. Para warga terdampak dari kebijakan pembangunan infrastruktur yang masif tersebut merupakan kelompok marjinal, yakni mereka yang secara struktural terpinggirkan dari akses mendapatkan manfaat ekonomi, sosial, dan politik, termasuk terpinggirkan untuk memeroleh akses keadilan karena berbagai keterbatasan. Secara teoretis, kemampuan kelompok-kelompok marjinal ini untuk mempertahankan hak-hak mereka dari kebijakan pembangunan infrastruktur sangat tidak setara dengan kekuasaan negara untuk mengimplementasikan kebijakan-kebijakannya. Sementara, kelompok-kelompok marjinal yang menjadi korban terdampak tidak memiliki kemampuan memadai untuk melakukan perlawanan (https://www.komnasham.go.id/files/20171101-laporan-tahunan-komnas-ham-tahun\$LZ3FPF.pdf).

Laporan tahunan Komnas HAM tahun 2016 ini relevan dengan kondisi Kampung 1001 Malam, lokasi yang dipilih sebagai objek dari kegiatan pengabdian masyarakat ini. Kampung 1001 Malam, adalah sebuah pemukiman yang berada di bawah kolong jembatan tol SurabayaGempol. Dinamai 1001 Malam, karena untuk bisa sampai di lokasi ini, kita mesti melewati jembatan tol Dupak yang gelap. Selain itu, kampung ini senantiasa dalam kondisi gelap karena kurangnya cahaya di bawah jembatan tol. Sehingga kapanpun waktunya, di kampung ini akan terasa seperti malam.

Kampung 1001 Malam merupakan satu lokasi hunian yang kumuh dengan jumlah penduduk kurang lebih 180 kepala keluarga. Terisolir dari perkampungan di sekitar kawasan Lasem Baru, akses menuju ke lokasi ini cukup berliku. Untuk bisa mencapai tempat itu kita harus melintasi jalan setapak di bantaran Kalianak, Morokrembangan, kemudian masuk ke bawah beton jalan tol. Belum cukup itu saja, kita masih harus melintasi kali menggunakan perahu tambang untuk mencapainya. Kampung yang 'lahir' mulai tahun 1999 ini akan menyambut pengunjung yang datang dengan gapura berupa kaki beton jembatan yang sekaligus menjadi pintu masuk perkampungan. Di sana, warga sudah terbiasa berjalan dengan kondisi harus membungkukkan badan.

Penghuni kampung 1001 Malam, rata-rata bekerja sebagai pengamen, pemulung, atau kuli bangunan. Awalnya, kampung ini lekat dengan stigma sebagai tempat pelarian pelaku tindak kriminal. Hal ini terjadi karena lokasinya yang bersebelahan dengan tol SurabayaGresik. Namun seiring banyaknya warga yang menghuni kampung sejak tahun 1999, kesan buruk itu perlahan memudar (El Rahman, 2019). Para penghuni kampung, adalah sebagian dari kaum marjinal yang tidak mampu mengikuti kencangnya laju pembangunan. Mereka terpinggirkan, tidak memiliki akses ekonomi, sosial, dan politik, bahkan tidak mendapat pengakuan atas hak hidup dan berkembang karena rata-rata tidak memiliki kartu identitas.

Realita ketimpangan hidup yang dialami warga Kampung 1001 Malam ini mendorong kami untuk melakukan sesuatu. Awalnya, kami berencana menyelenggarakan pendidikan gratis bagi anak-anak warga kampung. Tak mampu mengakses pembangunan dalam berbagai aspek, pendidikan bak impian yang utopia bagi anak-anak di sana. Kemiskinan yang menjerat orang tua mereka membuat anak-anak ini kehilangan hak menikmati pendidikan sebagaimana diamanatkan Undang-Undang Dasar 1945 kepada bangsa ini. Rencana ini terpaksa ditanggalkan ketika pandemi ternyata tidak hanya berlangsung 2-3 minggu sebagaimana 
dipahami saat awal-awal terjadi di bulan Maret 2020. Setelah melakukan penelitian mengenai kondisi warga, maka rencana melakukan pengabdian masyarakat dalam bentuk pendidikan gratis pun diubah dan akhirnya dipilihlah gagasan membuat video tentang Kampung 1001 Malam. Pembuatan video tersebut bertujuan untuk membantu menyuarakan kondisi warga di kampung tersebut. Memberi suara kepada mereka yang tidak mampu bersuara. Video ini diharapkan dapat menggugah para pihak terkait tentang kondisi warga. Bahwa mereka adalah fakta, realita, yang hidup berdampingan bersama kita, bersama tujuan pembangunan yang entah sejatinya ditujukan bagi siapa.

\section{METODE PELAKSANAAN}

Kegiatan pengabdian masyarakat ini diawali dengan melakukan penelitian atau riset lapangan. Subjek penelitian adalah seluruh kepala keluarga penghuni Kampung 1001 Malam sebanyak 180 orang. Metode yang dipilih adalah deskriptif kualitatif dengan teknik pengumpulan data yang beragam, mulai dari observasi, wawancara, dan dokumentasi. Metode kualitatif sebagaimana ditulis oleh Morissan (2012:22) merupakan pendekatan penelitian yang mendalam dan berorientasi pada sejumlah kecil kasus, termasuk satu studi kasus. Penelitian dengan metode kualitatif berupaya menemukan data secara terperinci dari kasus tertentu, seringkali dengan tujuan menemukan bagaimana sesuatu terjadi. Menurut Morissan, tujuan yang hendak dicapai dalam pendekatan kualitatif adalah membuat suatu fakta dapat dipahami. Pendekatan ini tidak menekankan pada generalisasi atau penarikan kesimpulan, atau prediksi dari berbagai data yang ditemukan dalam penelitian. Metode ini membantu peneliti untuk melihat perilaku objek penelitian dalam situasi yang riil tanpa adanya intervensi atau rekayasa sebagaimana terjadi pada penelitian dengan metode eksperimental atau survei (2012:22).

Dengan berbagai karakteristiknya, pendekatan kualitatif dianggap mengandung kelemahan. Pertama, ukuran sampel seringkali terlalu kecil untuk memungkinkan peneliti menarik sebuah kesimpulan dari data di luar sampel yang dipilih. Oleh karena itu penelitian dengan metode kualitatif seringkali dilakukan untuk penelitian pendahuluan sebelum penelitian yang lebih mendalam. Informasi yang dihasilkan dari penelitian dengan metode kualitatif dapat digunakan untuk mempersiapkan analisis kuantitatif yang lebih rigid. Kelemahan lain dari pendekatan kualitatif adalah soal realibitas data yang dihasilkan. Karena penelitian kualitatif umumnya dilakukan oleh satu orang atau sejumlah kecil peneliti, maka peneliti dianggap memiliki kemungkinan bias karena unsur subjektivitas. Kelemahan berikutnya adalah karena sifatnya yang fluid, penelitian dengan metode kualitatif yang tidak dipersiapkan dengan baik dapat berujung sia-sia, tidak menghasilkan data yang diharapkan (Morissan, 2012:23)

Dalam penelitian awal sebelum memutuskan program pengabdian masyarakat yang sesuai bagi warga Kampung 1001 Malam, dipilih metode kualitatif deskriptif. Sifat deskriptif ini sesuai dengan tujuan penelitian yang direncanakan yaitu untuk mengetahui situasi atau peristiwa dari subjek yang hendak diteliti. Dalam penelitian deskriptif, peneliti akan mengamati objek penelitiannya, mencatat, dan hasilnya akan menjadi temuan dari apa yang sudah diamatinya. Penelitian deskriptif yang dilakukan secara terukur dan terencana, dapat menghilangkan spekulasi atau persepsi yang muncul secara awam. Penelitian deskriptif merupakan pengamatan secara ilmiah yang dilakukan dengan hati-hati, cermat, dan terukur (Morissan, 2012:37).

Subjek dalam penelitian ini adalah seluruh Kepala Keluarga warga Kampung 1001 Malam yang berjumlah 180 orang. Teknik pengumpulan data dilakukan dengan menggunakan 
3 cara, yaitu observasi, wawancara, dan dokumentasi. Pada tahap observasi, dilakukan pengamatan dengan menggunakan instrumen lembar observasi meliputi:

a)kondisi fisik pemukiman (jarak antar bangunan, konstruksi jalan, dinding, atap, lantai, ventilasi, pencahayaan, fasilitas mandi cuci kakus (MCK), jaringan listrik, persampahan, sumber air bersih, drainase;

b)kondisi sosial (kesehatan, pendidikan, kegiatan masyarakat, dan ruang terbuka);

c)kondisi ekonomi (status pekerjaan, pendapatan, pendidikan, beban tanggungan).

Pada tahapan wawancara, penelitian dilakukan dengan menemui langsung tokoh masyarakat sekaligus pengelola tempat tersebut. Pertanyaan yang diajukan meliputi kondisi fisik, kondisi sosial, dan kondisi ekonomi warga di pemukiman kumuh Kampung 1001 Malam. Selain bertujuan mencapatkan data, wawancara sekaligus berfungsi sebagai sebuah mekanisme validasi dari observasi yang sudah dilakukan oleh peneliti. Sedangkan pada tahap dokumentasi, pengumpulan data dilakukan dengan cara mencatat kejadian yang ada di lapangan dengan memanfaatkan data sekunder yang ada. Dokumentasi dilakukan baik menggunakan pencatatan, foto, dan perekaman baik audio maupun audio visual.

\section{HASIL DAN PEMBAHASAN}

Kampung 1001 Malam, dihuni oleh kurang lebih 180 kepala keluarga. Untuk menuju ke lokasi, kita harus melintasi jalan setapak di bantaran Kali Anak, Morokrembangan. Setelah itu kita harus masuk ke bawah beton jalan tol lalu melintasi kali dengan menggunakan perahu tambang. Kampung ini mulai berpenghuni pada tahun 1999. Pemukiman 1001 Malam berawal dari area bawah kolong jalan tol Dupak yang tidak berpenghuni karena pembangunan jalan tol tersebut memang tidak diperuntukkan bagi pemukiman masyarakat. Awalnya, lokasi tersebut menjadi markas para 'bajing loncat'. Yakni orang-orang yang mencuri barang muatan dari atas kendaraan seperti truk yang sedang melintas. Seiring perkembangan kota, semakin banyak warga dari daerah yang melakukan urbanisasi. Surabaya, menjadi salah satu tujuan khususnya bagi warga sekitar Jawa Timur dengan harapan dapat memperbaiki nasib. Sayangnya, niat mengubah nasib tersebut tidak dibarengi dengan keterampilan atau keahlian tertentu. Akibatnya, bukannya menjadi lebih baik, para pendatang ini justru kian terpinggirkan. Pembangunan kota yang seharusnya bertujuan memberikan penghidupan yang lebih baik bagi masyarakat, nyatanya tidak dapat diakses para warga pendatang. Bahkan sekadar untuk mendapatkan tempat tinggal yang layak. Hal itu kemudian yang mendorong mereka membangun tempat tinggal seadanya dan bekerja apa saja demi menyambung hidup di Kampung ini.

Mayoritas warga Kampung 1001 Malam, bekerja sebagai pengemis, pengamen, atau pemulung. Banyak pula yang hanya menjadi pengangguran. Bagi warga kampung tersebut, uang adalah prioritas. Dalam konteks ini, uang hanyalah sekadar cukup untuk memenuhi kebutuhan primer yaitu pangan, alih-alih mencukupi kebutuhan keseharian. Dalam kondisi yang demikian, maka pendidikan adalah salah satu urusan yang dikesampingkan. Daripada melanjutkan sekolah, anak-anak dipekerjakan orang tuanya untuk menjadi pengemis. Pendidikan terakhir warga rata-rata SD dan SMP meski ada pula yang sempat mengenyam bangku SMA. 


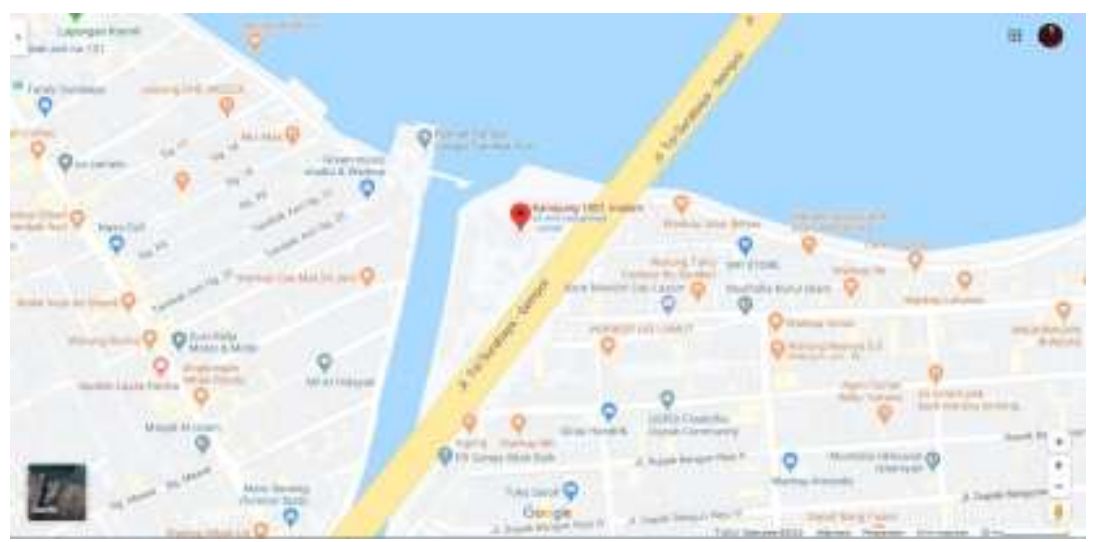

Gambar 1. Peta lokasi Kampung 1001 Malam (sumber: Google Maps)

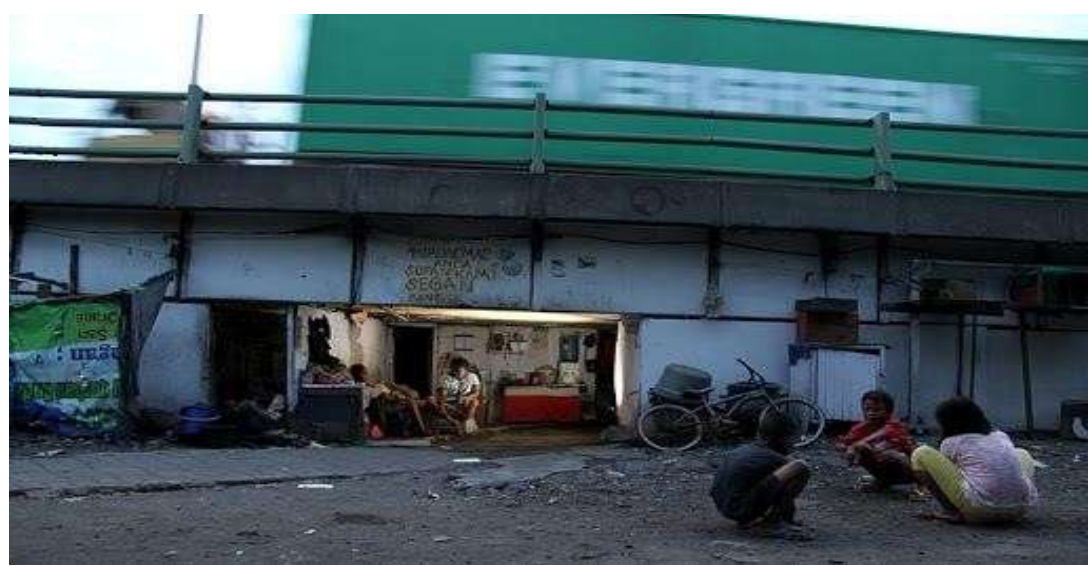

Gambar 2 Suasana Kampung 1001 Malam (Google Image)

Dari hasil wawancara yang dilakukan dengan warga Kampung 1001 Malam bernama Wanti (45), diperoleh informasi bahwa dari 180 Kepala Keluarga (KK) yang menempati area kampung tersebut, hanya sekitar $50 \mathrm{KK}$ yang benar-benar hidup di bawah kolong Tol Dupak. Sisanya memilih tinggal di sepanjang area pinggiran kolong tol. Warga yang tinggal di bawah kolong tol tersebut menempati rumah petak berukuran 3 x 2 meter yang rata-rata dihuni 4 orang.

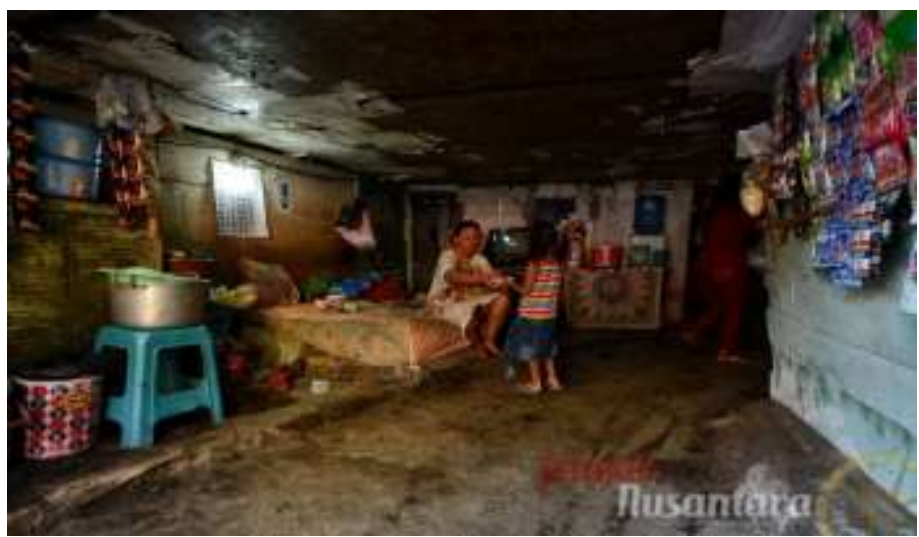

Gambar 3. salah satu rumah petak warga Kampung 1001 Malam

(https://jelajahnusantara.co/culture/perjuangan-di-kampung-1001-malam-surabaya-belum-berakhir/) 
Satu hal yang paling menarik perhatian adalah dengan kondisi pemukiman yang berada di bawah kolong jembatan tol, maka warga kampung yang bertinggi badan lebih dari $160 \mathrm{~cm}$ harus beraktivitas dengan menundukkan badan, duduk, atau berbaring. Selain kumuh karena kemiskinan struktural yang menjerat, pemukiman juga tidak sehat karena berhadapan langsung dengan sungai yang kotor, sampah di sana-sini, serta fasilitas MCK yang seadanya dengan jumlah terbatas.

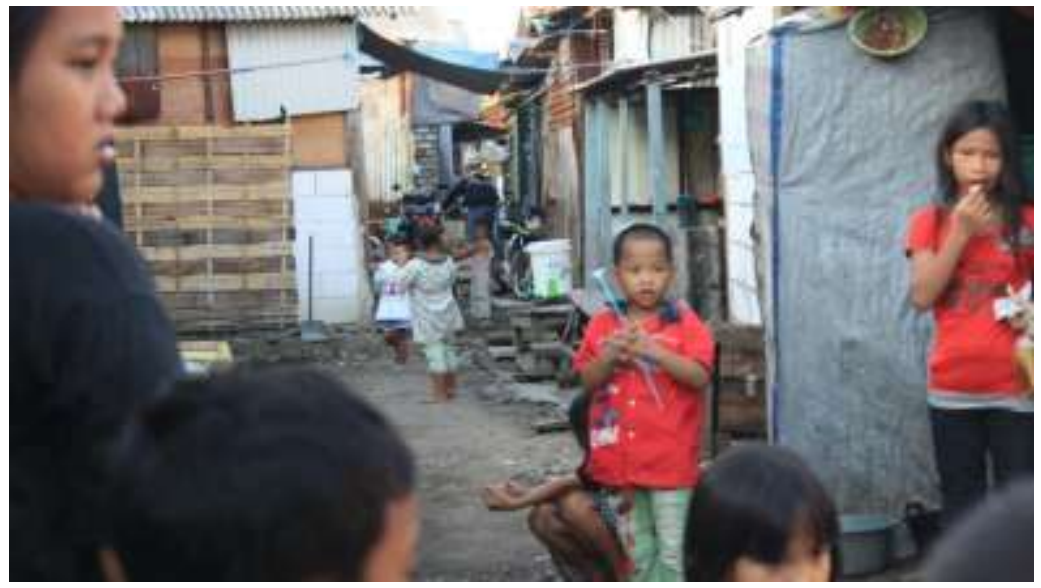

Gambar 4. Dokumentasi pemukiman Kampung 1001 Malam

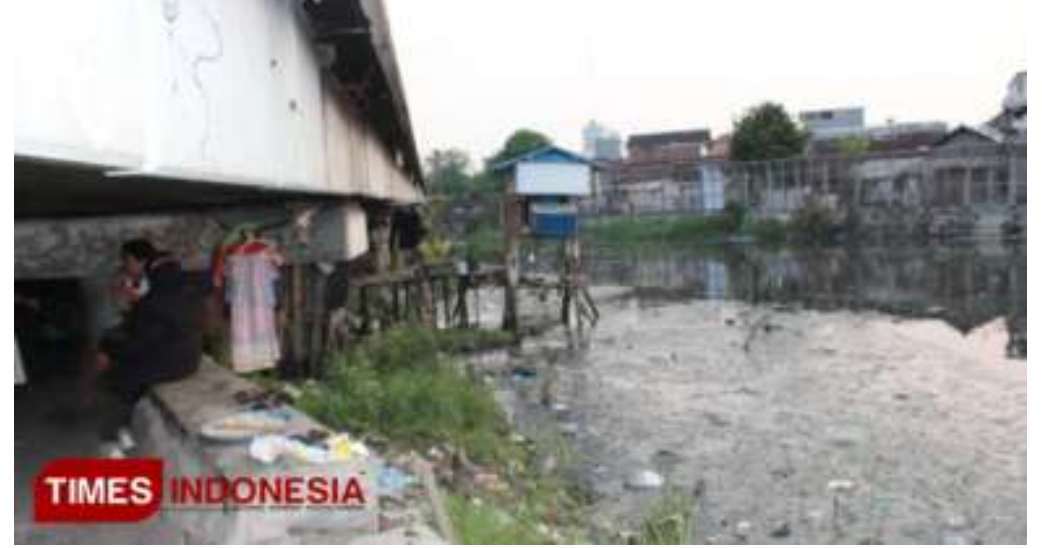

Gambar 5. Kondisi perkampungan kumuh

(https://www.timesindonesia.co.id/read/news/290401/melihat-kehidupan-kaum-marginal-di-kampung-1001malam-surabaya-di-tengah-pandemi)

Sebagian besar warga Kampung 1001 Malam bekerja sebagai pemulung, pengamen, pengemis, kuli bangunan, supir lepas, dan sebagian lagi pengangguran. Penghasilan sehari-hari seorang pemulung berkisar 30 ribu rupiah. Sementara penghasilan kuli bangunan sekitar 25 ribu rupiah. Nilai yang sangat rendah jika dibandingkan dengan Upah Minimum Kabupaten/Kota (UMK) Surabaya tahun 2020 berdasarkan Peraturan Gubernur mengacu pada aturan undang-undang dan Peraturan Pemerintah No. 78 Tahun 2015 tentang pengupahan yakni sebesar Rp 4.200.479,19.

Dari tingkat pendidikan, angka partisipasi sekolah warga Kampung 1001 Malam sangat rendah. Mayoritas harus rela putus sekolah sejak tingkat sekolah dasar. Pascaputus sekolah, anak-anak 'Kampung 1001 Malam' kemudian menyebar ke jalan raya untuk mengamen dan mengemis atau menjadi pemulung seperti orang tuanya. Sebuah kondisi yang ironis mengingat di Kecamatan Krembangan, tempat di mana Kampung 1001 Malam bernaung terdapat 41 
SD/MI, 18 SMP/MTs, 7 SMA/MA, dan 3 SMK sehingga total mencapai 69 sekolah (sumber: BPS Surabaya).

\section{Menggugat Hak Pendidikan Bagi Kaum Marjinal}

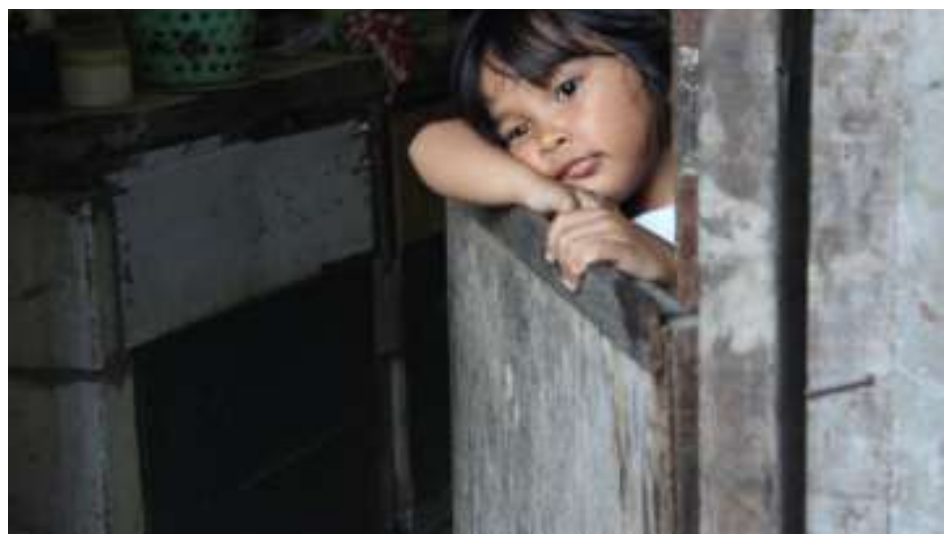

Gambar 6. Anak-anak warga Kampung 1001 Malam harus putus sekolah

\begin{tabular}{|l|c|c|}
\hline $\begin{array}{c}\text { Pendidikan } \\
\text { Terakhir }\end{array}$ & Jumlah & Persentase \\
\hline SD & 9 & $10 \%$ \\
\hline SMP & 18 & $12 \%$ \\
\hline Tidak Sekolah & 123 & $82 \%$ \\
\hline Total & 150 & $100 \%$ \\
\hline
\end{tabular}

Tabel 1. Jumlah Anak Putus Sekolah di Kampung 1001 Malam

Dari data yang diperoleh peneliti, diperoleh informasi bahwa pendidikan adalah sebuah kemewahan yang tidak dapat disentuh oleh anak-anak warga Kampung 1001 Malam. Kurangnya perhatian, dukungan, dari orang tua maupun lingkungan sekitar dan kemiskinan yang membelenggu orang tuanya menjadi penyebab putus sekolah. Mereka lebih memilih bekerja apa saja untuk membantu orang tua mereka mendapatkan uang, ketimbang bersekolah yang dianggap membuang-buang waktu dan tenaga, bahkan harus mengeluarkan biaya yang tidak mereka miliki. 


\section{Bukan Pilihan: Bertahan Di Permukiman Kumuh}

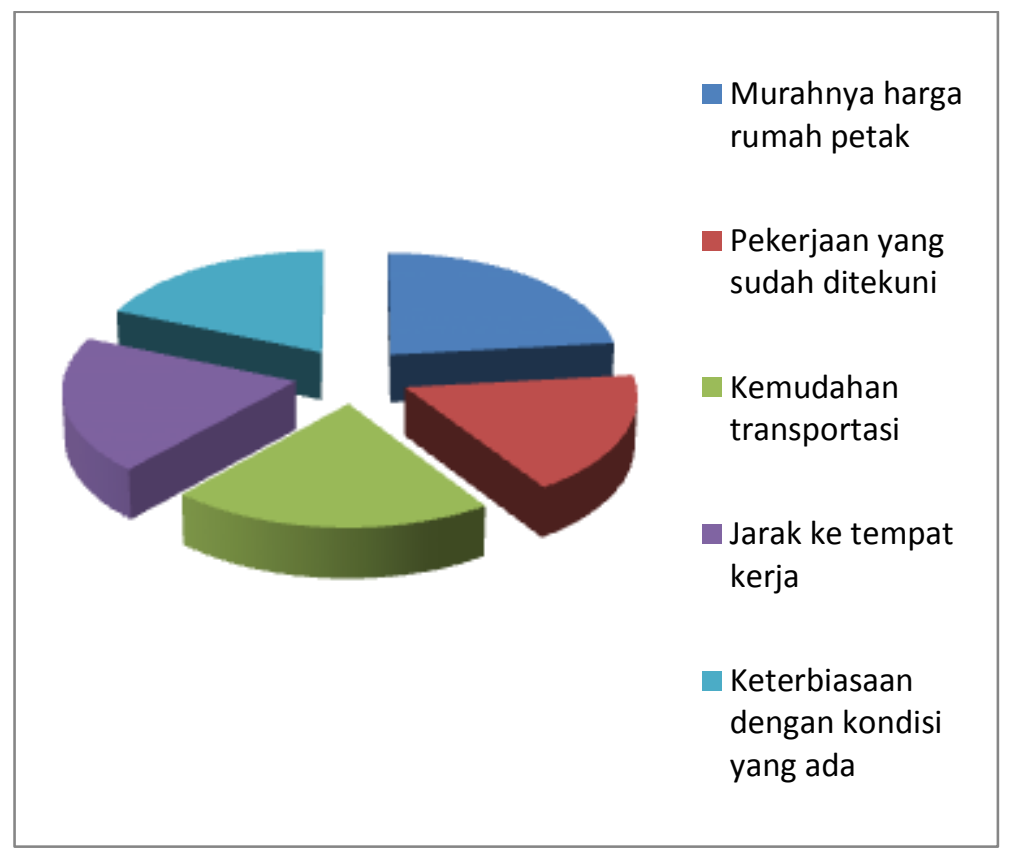

Diagram 1. Faktor yang membuat warga bertahan

Dengan kondisi yang begitu buruk di pemukiman tersebut mengapa warga bertahan? Dari hasil wawancara yang dilakukan diperoleh informasi tentang faktor-faktor yang membuat warga tetap bertahan dalam lingkaran kemiskinan di bawah tol. Kelima faktor tersebut adalah: 1)pekerjaan yang sudah mereka tekuni;

2)harga rumah petak yang dapat mereka jangkau;

3)jarak ke pusat kota/pusat aktivitas sehari-hari;

4)keterbiasaan dengan kondisi yang ada; dan

5)kemudahan transportasi.

Yang paling dominan dari semua faktor tersebut adalah faktor tempat tinggal yang dapat mereka jangkau dengan penghasilan yang mereka perolah (80\%). Mereka juga tidak memiliki pilihan untuk pindah dari tempat tersebut, karena mereka tidak memiliki tempat tinggal yang lain. Rata-rata warga Kampung 1001 Malam berasal dari luar kota Surabaya, yang sudah tidak memiliki tempat tinggal di kampungnya.

\section{PENUTUP}

Kondisi warga di Kampung 1001 Malam sebagaimana dipaparkan dalam tulisan ini mendorong kami untuk membuat sebuah video dokumenter. Dalam video berdurasi 2 menit 58 detik ini, kami mencoba menggambarkan bagaimana warga kampung harus menjalani keseharian mereka dalam segala keterbatasan. Rencana untuk menyelenggarakan pendidikan gratis bagi anak-anak Kampung 1001 Malam yang putus sekolah belum dapat terlaksana karena adanya pandemi COVID-19. Sebagai gantinya, kami memberikan paket bantuan pendidikan kepada warga yang harapannya dapat menjadi fasilitas belajar bagi anak-anak, meski sangat terbatas. 
Video dokumenter kami laporkan sebagai bagian yang menyatu dengan artikel ini, wujud pengabdian kami dari masyarakat akademis di bidang ilmu komunikasi agar dunia melihat ketimpangan dan ketidakadilan kelompok-kelompok marjinal yang terpinggirkan, bahkan tepat di bawah simbol pembangunan itu sendiri: jalan tol.

\section{DAFTAR PUSTAKA}

El Rahman, Vanny. (2019). 10 Foto Kampung 1001 Malam, Hunian Gulita di Kolong Tol. Dikutip dari https://jatim.idntimes.com/news/jatim/vanny-rahman/10-foto-kampung-1001malam-hunian-gulita-di-kolong-tol.

Morissan, M.A. (2012). Metode Penelitian Survei. Jakarta: Kencana.

Prasetya Widodo, H. (2020). Use Of Social Media By The Tourism And Culture Office Of Malang Regency To Increase The Number Of Tourist Visits In Malang Regency. Jurnal Spektrum Komunikasi, 8(1), 94-103. https://doi.org/10.37826/spektrum.v8i1.71

Suprihatin. (2019). Identitas Diri Perempuan di Facebook. Jurnal Spektrum Komunikasi, 7(1), 62-77. https://doi.org/10.37826/spektrum.v7i1.30

Suprihatin, (2020). Critic Towards Legislative Candidates In\# Unboxingcaleg. Jurnal Nomosleca, 6(2), 77-89.

https://www.komnasham.go.id/files/20171101-laporan-tahunan-komnas-ham-tahun\$LZ3FPF.pdf

https://jelajahnusantara.co/culture/perjuangan-di-kampung-1001-malam-surabaya-belumberakhir/

https://www.timesindonesia.co.id/read/news/290401/melihat-kehidupan-kaum-marginal-dikampung-1001-malam-surabaya-di-tengah-pandemi)

https://surabayakota.bps.go.id 